\title{
3D TEXTURED MODELLING OF BOTH EXTERIOR AND INTERIOR OF KOREAN STYLED ARCHITECTURES
}

\author{
Jin-Duk Lee ${ }^{\text {a }}$, Kon-Joon Bhang ${ }^{\text {a }}$, Walter Schuhr ${ }^{\text {b }}$ \\ ${ }^{a}$ Dept. of Civil Engineering, Kumoh National Institute of Technology, 61 Daehakro, Gumi, Gyeongbuk, South Korea - \\ (jdlee, bhang.1)@kumoh.ac.kr \\ ${ }^{\mathrm{b}}$ Faculty of Water, Environment, Civil Engineering and Security, University of Applied Sciences \\ Magdeburg, Breitscheidstr. 2, 39114 Magdeburg, Germany - schuhr3d@ hotmail.com
}

KEY WORDS: Terrestrial Laser Scanner, 3D Modelling, Traditional Architectures, Cultural Assets, Spatial Information

\begin{abstract}
:
This paper describes 3D modelling procedure of two Korean styled architectures which were performed through a series of processing from data acquired with the terrestrial laser scanner. These two case projects illustate the use of terrestrial laser scanner as a digital documentation tool for management, conservation and restoration of the cultural assets. We showed an approach to automate reconstruction of both the outside and inside models of a building from laser scanning data. Laser scanning technology is much more efficient than existing photogrammetry in measuring shape and constructing spatial database for preservation and restoration of cultural assets as well as for deformation monitoring and safety diagnosis of structures.
\end{abstract}

\section{INTRODUCTION}

Laser has the merits that are able to obtain a large number of measurements with high precision and high resolution in a short time and one of concrete realizations is a terrestrial laser scanner called terrestrial LIDAR. Laser scanners are used more and more as surveying instruments for various applications. Accurate drawings are needed for improvement of construction of both of building exterior and interior. However if the design drawings of that time of construction work were lost or damaged or actual dimensions of drawings differ from those of design drawings, the interior or exterior should be resurveyed. In this study, the generation process of 3D models were suggested through using laser scanning and related reverse engineering technology. Reverse engineering is the technology which reconstructs shape. It comprises of three steps i.e. measuring real world object, converting measured data to structured point-cloud and constructing 3D CAD model or 3D shape, which can be used for comparison or reconstruction, with texture from point-cloud as the technology which reconstructs shape. On-site 3D scanning is virtually unlimited in size and environment including broad daylight, the dark of night, indoors, and outdoors. It collects high-density spatial imaging with millions of coordinates quickly and accurately with cameras and other measurement devices.

Using highly accurate $3 \mathrm{D}$ scan data generated with $3 \mathrm{D}$ scanning, we are able to view as-built documentation in a virtual world and obtain permanent records for immediate or future uses. The point cloud data can also be surfaced to generate a CAD model.

3D laser scanning technology can acquire high density point data in an accurate and rapid way, digitize all the 3D spatial information about a real world object and allow constructiong digital surface models that accurately represent surface variability. It has been utilized for realizing accurate shape not in contact with the object which needs preservation and restoration such as cultural assets, buildings, structures and so forth and extracting spatial information from stored digital data.

This paper illustrates the procedure that $3 \mathrm{D}$ modellings are performed through a series of processing from data acquired with the terrestrial laser scanner on the supposition that two Korean styled buildings are historic architectures. These two case studies show the potential for the use of digital documentation tool for the cultural assets including management, conservation and restoration of them.

\section{ACTUAL MEASUREMENT AND 3D MODELING USING TERRESTRIAL LASER SCANNER}

\subsection{Equipment}

The 3D laser scanner equipment used for this study is $\mathrm{Z}+\mathrm{F}$ IMAGER 5010C model produced by Zoller+Frohlich co. as shown in Figure 1. It can collect high-quality panoramic color imagea with horizontal range of $360^{\circ}$ as HDR (i-cam) is built in it.

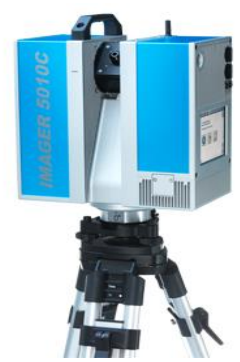

Figure 1. Terrestrial laser scanner(Z+F IMAGER 5010C)

\begin{tabular}{|c|c|}
\hline maximum distance & $187 \mathrm{~m}$ \\
\hline minimum distance & $0.3 \mathrm{~m}$ \\
\hline resolution & $0.1 \mathrm{~mm}$ \\
\hline
\end{tabular}




\begin{tabular}{|c|c|}
\hline collection speed & $<500,000 \mathrm{pxl} / \mathrm{s}$ \\
\hline Accuracy & $1 \mathrm{~mm}$ \\
\hline vertical revolution & $310 \mathrm{deg}$. \\
\hline horizontal revolution & $360 \mathrm{deg}$. \\
\hline camera & HDR camera \\
\hline
\end{tabular}

Table 1. Specification of Z+F IMAGER 5010C

Terrestrial LIDAR measures and register relative coordinates and then measured data are downloaded from receiver apparatus to Notebook PC

\subsection{Case Study 1}

The Korean styled pavilion with about 5 meter in diameter and about 7 meter in height was selected as an object. Laser scanning data were acquired sequentially at five stations as shown in Fig.2 and eight control points were surveyed by total station.

Table 2 shows $\mathrm{X}, \mathrm{Y}, \mathrm{Z}$ coordinates of eight control points surveyed by a total station.

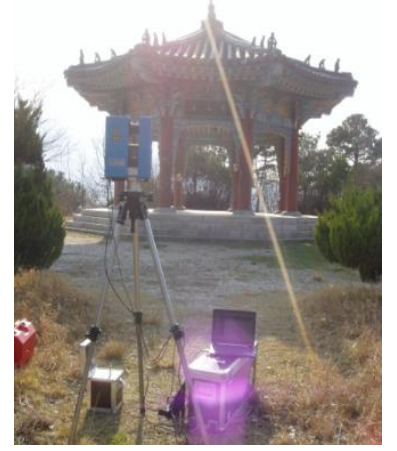

Figure 2. Data acquisition scene

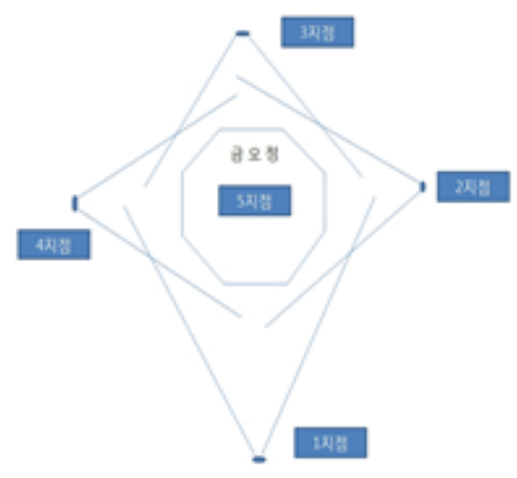

Figure 3. Five stations of Terrestrial LIDA

\begin{tabular}{|c|c|c|c|}
\hline No. & $\mathrm{X}(\mathrm{m})$ & $\mathrm{Y}(\mathrm{m})$ & $\mathrm{Z}(\mathrm{m})$ \\
\hline 101 & 5000 & 5003.509 & 100.268 \\
\hline 102 & 4997.485 & 5002.52 & 99.634 \\
\hline 103 & 4996.356 & 5000.056 & 99.998 \\
\hline 104 & 4997.309 & 4997.516 & 100.219 \\
\hline 105 & 4999.767 & 4996.412 & 99.717 \\
\hline 106 & 5002.331 & 4997.35 & 99.006 \\
\hline 107 & 5003.436 & 4999.792 & 99.662 \\
\hline 108 & 5002.525 & 5002.34 & 98.803 \\
\hline
\end{tabular}

Table 2. The coordinates of control points

Data weight was reduced to one-third original data by passing filtering process which delete unnecessary noisy data and software searches and erases automatically $0.0074 \mathrm{~mm}$ of optimal distance interval between adjacent points. And then after going through polygon process, surface process, merge of shells and error correction, 3D model as shown in Figure 4. was completed.

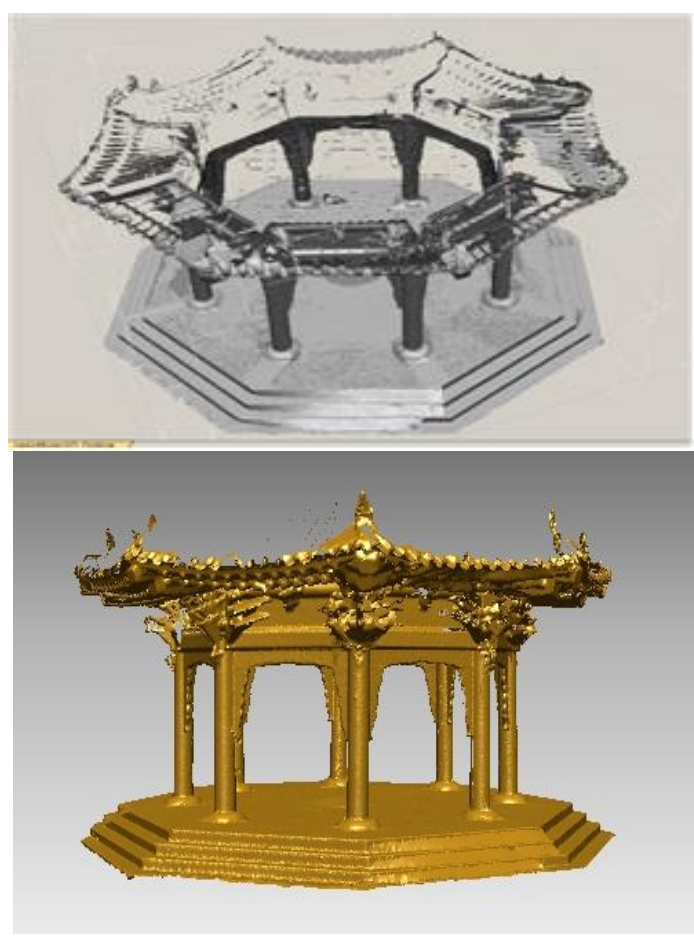

Figure 4. 3D modelling of the pavilion

\subsection{Case Study 2}

Korean traditional house was selected as second experimental object. Total ten laser scanning stations were planned around it to cover all over the wall of the object as shown in Figure 5. St.1 to St.9 were considered for covering building exterior and St.10 was for covering building interior. Above all, when selecting St.1 and St. 10 , we had to consider overlapping area which is covered commonly at both stations beforehand.

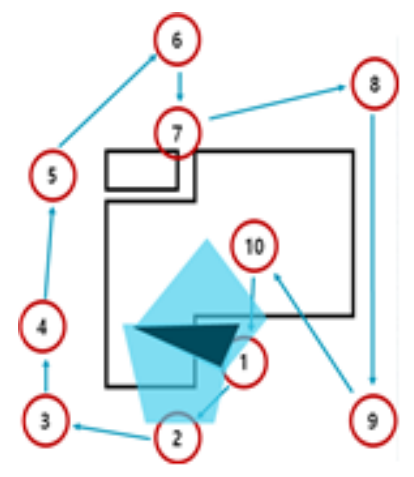

Figure 5. Ten laser scanning stations 
Postprocessing was conducted with Z+F Laser Control program. Through filtering for noise erase and image matching, 3D modelling was conducted. Figure 6, Figure 7 and Figure 8 illustrate 3D textured models of the exterior surface of the building which were generated respectively at Station 1, Station 4 and Station 6. Figure 9 shows 3D textured models of the building inside which were generated at Station 10.

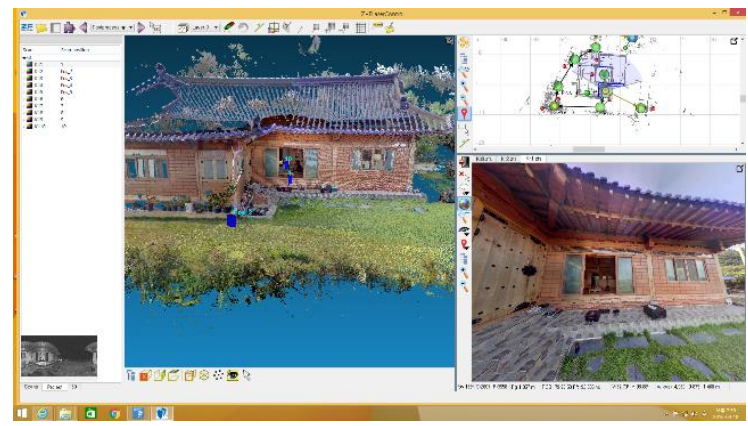

Figure 6. 3D model generated at Station 1 and photo image

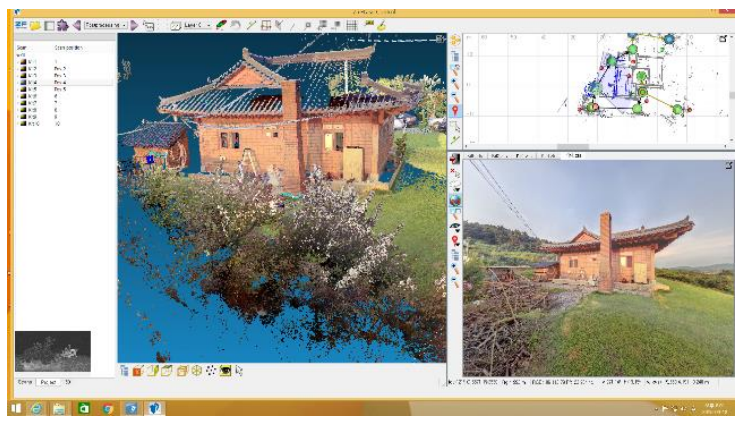

Figure 7. 3D model generated at Station 4 and photo image

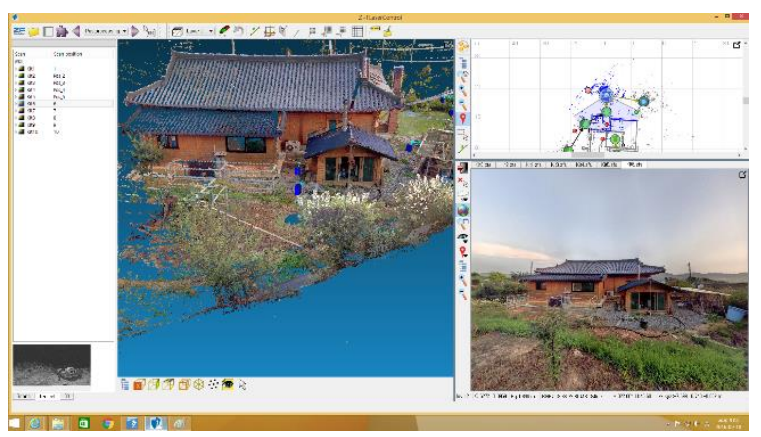

Figure 8. 3D model generated at Station 6 and photo image

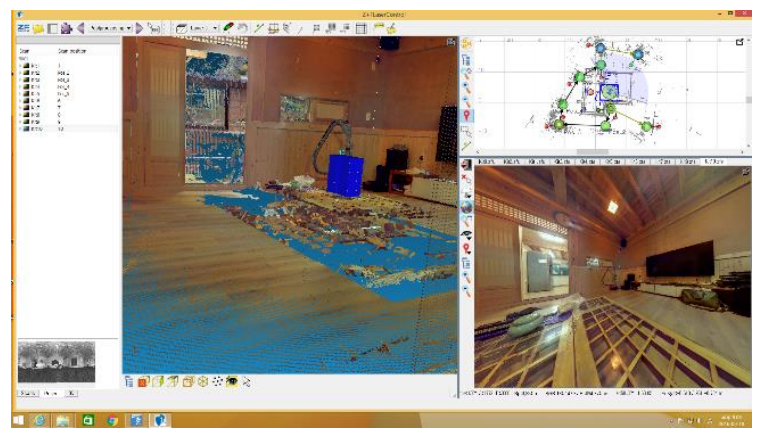

Figure 9. 3D model of building inside generated at Station 10 and photo image

\section{CONCLUDING REMARKS}

As data of not simple images but digital concept are usually required in order to acquire spatial information of cultural assets, historic building and so forth and record and preserve data of them, complete 3D shape data should be produced by applying reverse design technology.

Because laser or optic method measured out of touch with the object have merits of high speed and high precision, it is recommended as the best practice for acquiring 3D spatial information of cultural assets, historic buildings and so on.

An original result obtained by laser scanning is just basic data for an end product in itself as point-cloud data composed of numerous points and therefore complete 3D data can not be produced till passing through postprocessing using appropriate software.

Once point-cloud data are converted to $2 \mathrm{D}$ or $3 \mathrm{D}$ CAD model, they will be able to be utilized for not only fundamental data for recording and preserving of shape information old buildings but academic data through application and management of data.

Not only Restore damaged part by measuring straightness of straight line section and bending radius of curved section and the rate of change of area or volume in the object but also acquire volume, weight and slope of it and extract data for structural monitoring of old architectures from CAD data stated above.

Point cloud data of 3D scanning are convertible not only 3D CAD models but also BIM integration, as-built documentation, fly-through and presentation capabilities with more accuracy than photos or video alone, elevation drawings, plan view drawings in the deliverables of laser scanning according to the needs of our clients or depending on intended use.

In the future, database building technology based on 3D scanning is expected to turn itself into core technology for preserving and restoring cultural heritages and to be extensively applied to geographic information-related contents, mobile-related contents and so on.

\section{REFERENCES}

Arayici, Y., 2007. An Approach for Real World Data Modelling with the 3D Terrestrial Laser Scanner for Built Environment, Automation in Construction, Vol.16, No.6, pp. 816-829.

H.T. Ahn, 2000. Analysis of Cultural Asset Using Point Scanning System, Master Degree Thesis, Pusan University.

S.J. Sa, I.P. Lee, Y.S. Choi and E.J. Oh, 2000. 3D

Precision Building Modeling Based on Fusion of Terrestrial LiDAR and Digital Close-Range, Proceeding of Korean Cadastral Society.

S.H. Han, Y.S. Bae and S.H. Bae, 2006. Application Analysis of Digital Photogrammetry and Optical Scanning 
Technique for Cultural Heritages, Journal of the Society of Korea Civil Engineers, Vol.26, No.5, pp.869-876.

C.D. Jeong, J.M. Oh and S.Y. Kim, 2010. Accuracy Analysis Of Building Outline Extracted From Terrestrial Laser Scanner Data, Proceeding of the Society of Korean Geo-Spatial Information, pp11-18.

https://www.laserdesign.com/3d-scanning-building-

facilities

J.D. Lee, J.B. Lee and S.H. Han, "Utilizing Terrestrial Laser Scanner for Extracting Plane Figures of Building Interior", Proceeding of ICCC2008, Hanoi, December 2008, pp.468-472. 